\title{
Variation in Plumage Coloration of Northern Cardinals in Urbanizing Landscapes
}

\author{
A Senior Honors Thesis \\ Presented in Partial Fulfillment of the Requirements for graduation with \\ research distinction in the undergraduate colleges of The Ohio State \\ University \\ by \\ Todd M. Jones \\ The Ohio State University \\ March 2009 \\ Project Advisor: Dr. Amanda D. Rodewald
}




\begin{abstract}
Despite decades of study, biologists know relatively little of how one of the most important avian phenotypic signals, feather coloration, may be affected by anthropogenic disturbances resulting from urbanization. From 2006-2008, I examined the relationship between urbanization and the carotenoid-based plumage color in Northern Cardinal (Cardinalis cardinalis) breeding in 13 riparian forests distributed across a rural-to-urban landscape gradient in central Ohio, USA. Color analysis from feathers collected each year from territorial breeding individuals (131 males and 149 females) indicated that plumage had more red hues with improving body condition for males and weakly for females. However, the amount of urbanization surrounding the forests in which cardinals bred was not related to coloration of either males or females. This study provides evidence that male plumage coloration of Northern Cardinals may serve as an effective indicator of individual condition. Also, the lack of a relationship between plumage coloration and urbanization suggests that urbanizing landscapes do not influence the ability of cardinals to sequester carotenoid-rich sources of food.
\end{abstract}

\title{
Introduction
}

Most studies of birds in human-dominated landscapes have described striking and relatively predictable patterns in the response of species diversity and abundance to the intensity of urban development (Blair 1996, Anderies et al. 2007, Devictor et al. 2007, Tratalos et al. 2007). Fewer investigations have examined more subtle consequences of urbanization, such as changes in reproduction, behavior, or coloration. Indeed, despite a century of interest in the causes and consequences of plumage coloration in birds 
(Anderson 1994, Bortolotti 2006), biologists continue to have a poor understanding of how urbanization might influence this important phenotypic signal.

Only a small number of studies have examined links among urbanization and coloration, the majority of which have focused on the detrimental effects of anthropogenic pollution upon colorations of adult and nestling Great Tits (Eeva et al. 1998, Isaksson et al. 2005, Isaksson and Andersson 2007). Others studies, such as Mulvihill et al (1992), have indirectly studied aspects of urbanization by observing how introduced exotic plant species altered the coloration of tail feather rectrices in Cedar Waxwings. However, with only these select few studies, the consequences of urbanization affecting avian coloration remain virtually undescribed.

Urban development may influence plumage coloration of birds by altering food resources or affecting individual health by mediating interactions with competitors, predators, or contaminants. For example, cities generally contain a variety of novel food resources, including bird-seed at feeders, fruit from exotic plants, and refuse that can change diet. The link between diet and plumage coloration should be particularly strong for species that have carotenoid-based plumages, which are highly dependent on carotenoid pigments obtained from food sources (Møller et al. 2000, McGraw et al. 2001, Hill et al. 2002). In addition, stress factors, such as human-commensal predators, oxidative stressors such as pollution, and increased avian densities, may constrain the ability of individuals to forage or to sequester obtained carotenoids for color-production rather than other physiological functions (Møller et al. 2000, Isaksson and Andersson 2007). Consistent with this idea, others have reported that higher quality diet-dependent plumages reflect better general health or immunocompetence (Andersson 1994, Saks et 
al. 2003, Jawor and Breitwisch 2004, Dawson and Bortolotti 2006, Maney et al. 2008), individual quality (Hill 1991, Kristiansen 2006), and quality of the environment in which birds live (Arriero and Fargallo 2006). Thus, in this way, coloration patterns might be useful indicators of cryptic detrimental or beneficial effects of urbanization upon an ecosystem.

Using the Northern Cardinal (Cardinalis cardinalis) as a model species, this study examined the extent to which coloration and body condition varied with the amount of urbanization surrounding forested parks in central Ohio. The Northern Cardinal is a socially monogamous, dichromatic, year round residential passerine species that exhibits a single annual molt just after the breeding season (Halkin and Linville 1999). They also display a brilliant red carotenoid-based plumage that is highly dependent upon their diet (Linville and Breitwisch 1997, McGraw et al. 2001). Cardinals are known to respond positively to urbanization, likely as a consequence of the more abundant nesting substrates, fruit resources, birdfeeders, and warmer winter temperatures than found in comparably rural landscapes (Leston and Rodewald 2006, Rodewald and Bakermans 2006;). Indeed, previous studies have found that forests within urban landscapes contain nearly three times the amount of fruit and nearby birdfeeders as rural forests (Atchison and Rodewald 2006, Leston and Rodewald 2006), largely resulting from the presence of exotic and invasive species, such as Amur honeysuckle (Lonicera maackii) and multiflora rose (Rosa multiflora). These increased food resources represent one of many examples of how urbanization may be influencing the general health of cardinals.

My honors research aimed to understand links between urbanization and plumage coloration in Northern Cardinals. Specifically, I asked the following questions: (1) Is 
body condition or size predictably related to plumage coloration, as measured by hue, saturation, brightness, and the variability of these metrics? and (2) To what extent does coloration vary along a rural-to-urban landscape gradient?

\section{Methods}

\section{Study Sites}

Cardinals were studied at 13 riparian forest sites within the Scioto River Watershed of central Ohio, USA (Table 1, modified from Rodewald and Shustack 2008). Study sites consisted of mature forest corridors $\geq 250 \mathrm{~m}$ long and $\geq 100 \mathrm{~m}$ wide; with all study sites existing at least 2-km apart from one another. Across the study area, riparian forests were generally similar in both shape and landscape configuration (i.e., they were narrow, linear, highly-connected forests in fragmented landscapes).

Landscape composition within a 1-km radius of each site was calculated based on digital orthophotos (2002-2004) and previously existing data from county auditors. Using these data, an urban index was calculated for each site to represent the amount of urbanization surrounding that particular forest. Positive values of the urban index indicate increasingly urban forests, which were generally surrounded by $>800$ buildings within the 1-km radius, and bordered by residential or commercial areas. By contrast, negative urban index values represent more rural forests, which were generally surrounded by $<360$ buildings and bordered by agricultural fields or pastures (Rodewald and Shustack 2008).

\section{Feather Sampling}

Feather samples were collected from 270 Northern Cardinals captured in mist nets during the breeding season, which ran from early March to mid-August 2006-2008. Six 
to ten feathers were collected from the breast of each male while three to six feathers were collected from the underwing coverts of each. These areas of feather collection were chosen because they are considered to be important areas for cardinal coloration and have been the focus of color measurements in previous studies (Linville and Breitwisch 1997, Wolfenbarger1999a, b, Jawor et al. 2003, Jawor et al. 2004). After collection, feathers were stored in packets and placed into a freezer until measurements were taken.

The following measures of body condition and size were also collected during the time of capture for each of the cardinals: tarsus length (nearest $0.1 \mathrm{~mm}$ ), weight $(\mathrm{g})$, and length of the unflattened right wing chord (nearest $0.5 \mathrm{~mm}$ ).

\section{Color Measurements}

Feathers from each individual were superimposed in layers of three on $4.5 \times 7.5 \mathrm{~cm}$ white note cards in order to maximally cover the white card behind them and to imitate the plumage surface of a bird (Bennett et al. 1997, Quesada and Senar 2006; Fig. 1). Superimposed feathers were then photographed using a Fujifilm FinePix S8000fd digital camera using it’s supra macro feature. In order to ensure standardized lighting conditions, photographs were taken inside an $8 \times 8 \times 8$ inch Digital Concepts Lighting Studio (with two 20 watt lights pointed at the feathers) and the camera was positioned $2 \mathrm{~cm}$ from the feathers. Pictures were taken with identical lighting and camera settings to ensure consistency. Images were then imported into Adobe Photoshop CS $2^{\mathrm{TM}}$, a program which quantifies hue, saturation, and brightness. In the program, hue is defined as a certain point on the color spectrum and is measured on a circular scale in degrees, with $0^{\circ}\left(360^{\circ}\right)$ being most red. The program quantifies saturation as a percentage of density, with $0 \%$ being least dense and $100 \%$ being most dense. Brightness is quantified on a percentage 
grayscale, with $0 \%$ being black and $100 \%$ being white. In order to quantify plumage coloration the color picker tool ( $3 \times 3$ eye-dropper sample) was used to take ten random point measurements within the largest overlapping area of the superimposed feathers. The mean value of these measurements was then calculated to obtain a representative value of plumage coloration for each individual. Although this method of quantifying coloration is similar to those that have been widely used (Kilner 1997, Kilner and Davies 1998, Dale 2000, Gerald et al. 2001, Fitze and Richner 2002, Bortolotti et al. 2003, Bezzerides et al. 2007, Surmaki and Nowakowski 2007), it does not necessarily represent the true plumage coloration of individuals. That is, the measurements taken may not be a true reflection of how Northern Cardinals view one another's plumage coloration (i.e. measurements are taken by a human perspective). Also, this method is not sensitive to UV light as perceived by birds (Cuthill 2006), though previous studies involving carotenoid plumages reported positive correlations among yellow-red spectrum (500nm-700nm) and UV reflectance peaks (Senar and Quesada 2006) which may make such measures redundant.

\section{Data Analysis}

I examined relationships between coloration and body condition by first creating a condition index. To do this, I used the program SAS to first apply a principal component analysis to wing and tarsus lengths. The first factor explained $67 \%$ of the variation in body size (eigenvalue $=1.34$ ) and loaded positively for both wing and tarsus $(0.818$ for both). This body-size factor was then regressed against mass for 131 males and 149 females. Mass was positively associated with body size for both males $\left(F_{1,129}=9.59, P=\right.$ 0.0024 $)$ and females $\left(\mathrm{F}_{1,147}=23.82, \mathrm{P}=<0.0001\right)$. Residuals obtained from these models were used as a body condition index, which indicated if individuals were heavier or 
lighter than expected for a given body (frame) size. The residuals were then regressed against hue, saturation, and brightness values.

To examine relationships between coloration and the amount of urbanization within the landscape surrounding forests, I treated "site" as the replicate. Coloration measurements were averaged over individuals and years to produce single hue, saturation, and brightness values by sex at each site. Using the program SAS, mean color metrics were then regressed against the urban index. Among-individual variation in coloration was determined by calculating the standard deviation in coloration among individuals over years, using "site" as the replicate. In order to determine the relationship for among-individual variation and the amount of urbanization surrounding forests, these standard deviation calculations were regressed against the urban index.

\section{Results}

I found evidence that body condition was related to plumage coloration. Most notably, all coloration parameters of male cardinals were associated with body condition. Hue and saturation of males were negatively associated with body condition (Hue, $ß=$ $0.41 \pm 0.10 \mathrm{SE} ; \mathrm{F}_{1,124}=17.58, \mathrm{P}=<0.0001$, Fig. 2 ; Saturation, $ß=-0.25 \pm 0.07 \mathrm{SE} ; \mathrm{F}_{1,124}=$ 13.40, $\mathrm{P}=0.0004$, Fig. 3), meaning that redness increased with improving condition. Brightness of male plumage marginally increased with body condition ( $ß=0.28 \pm$ 0.15SE; $F_{1,124}=3.59, P=0.0603$, Fig. 4). For females, plumage hue marginally decreased with body condition ( $\left(=-0.12 \pm 0.06 \mathrm{SE} ; \mathrm{F}_{1,141}=3.54, \mathrm{P}=0.0620\right.$, Fig. 5 ), in other words, female underwing covert redness increased with improving body condition. On the other hand, plumage saturation and brightness of females was not significantly related to body 
condition (Saturation, $ß=0.02 \pm 0.13 \mathrm{SE} ; \mathrm{F}_{1,141}=0.02, \mathrm{P}=0.8764$; Brightness, $ß=-0.03 \pm$ $\left.0.11 \mathrm{SE} ; \mathrm{F}_{1,141}=0.07, \mathrm{P}=0.7954\right)$.

Mean hue of female cardinal plumage did not vary with the amount of urbanization surrounding riparian forests ( $\left(=0.16 \pm 0.29 \mathrm{SE} ; \mathrm{F}_{1,11}=0.30, \mathrm{P}=0.5932\right)$, neither did saturation ( $\left(=-0.74 \pm 0.60 \mathrm{SE} ; \mathrm{F}_{1,11}=1.52, \mathrm{P}=0.2440\right)$ or brightness $(ß=$ $\left.0.282 \pm 0.46 \mathrm{SE} ; \mathrm{F}_{1,11}=0.37, \mathrm{P}=0.5552\right)$. Furthermore, no significant relationship between urbanization and among-individual variation in female coloration was detected (Hue, $ß=-0.013 \pm 0.21 \mathrm{SE} ; \mathrm{F}_{1,11}=0.00, \mathrm{P}=0.9510$; Saturation, $\beta=0.15 \pm 0.51 \mathrm{SE} ; \mathrm{F}_{1,11}=$ 0.09, $\mathrm{P}=0.7701$; Brightness, $\beta=-0.14 \pm 0.46 \mathrm{SE} ; \mathrm{F}_{1,11}=0.09, \mathrm{P}=0.7706$ ).

As with females, plumage coloration of males was not significantly related to the amount of urbanization surrounding riparian forests (Hue, $ß=0.39 \pm 0.29 \mathrm{SE} ; \mathrm{F}_{1,11}=1.79$, $\mathrm{P}=0.2079$; Saturation, $ß=0.31 \pm 0.19 \mathrm{SE} ; \mathrm{F}_{1,11}=2.70, \mathrm{P}=0.1286$; Brightness, $\beta=-0.32 \pm$ 0.29SE; $\left.\mathrm{F}_{1,11}=1.24, \mathrm{P}=0.2894\right)$. However, among-individual variation in male plumage saturation declined with the amount of urbanization surrounding riparian forests $(ß=-0.24$ \pm 0.10 SE; $F_{1,11}=5.88, P=0.0337$, Fig. 6). I found no evidence of a significant relationship between urbanization and variation in either hue ( $\left(=0.06 \pm 0.23 \mathrm{SE} ; \mathrm{F}_{1,11}=\right.$ 0.06, $\mathrm{P}=0.8049)$ or brightness $\left(\Omega=-0.14 \pm 0.38 ; \mathrm{F}_{1,11}=0.13, \mathrm{P}=0.7214\right)$.

\section{Discussion}

This study provides weak support for the idea that urbanizing landscapes influence plumage coloration in one synanthropic species, the Northern Cardinal. Although I found some evidence that males occupying urban forests were less variable in plumage saturation, birds occupying forests along the rural-to-urban gradient did not consistently vary in hue, saturation, or brightness of plumage. 
The more striking result from my work is that it provides additional evidence that coloration might be a good predictor of body condition, particularly for males. Plumage of males in better condition contained more pure red tones (i.e., hue) compared to males of comparatively poorer condition, a relationship that is consistent with previous studies (Wolfenbarger 1999c, Jawor and Breitwisch 2004). Others have reported that plumage coloration in cardinals reflects other indicators of individual quality, such as quality of territories occupied (Wolfenbarger 1999b), ornamentations (Jawor and Breitwisch 2004), and parental quality (Linville et al. 1998). Cardinals have even been shown to exhibit assortative mating with regard to their coloration (Jawor et al. 2003). In this way, coloration may serve as a useful cue in mate selection (e.g., sexual selection; Darwin 1871; Andersson 1994).

My findings that among-individual variation in plumage was not consistently related to urbanization (with the exception of variation in male saturation - a metric that decreased with urbanization) provides interesting insight into underlying dynamics of urban environments. In general, carotenoids are considered to be a limiting resource among birds displaying carotenoid-based plumages (Møller et al. 2000, Dale 2006) even for Northern Cardinals specifically (Linville and Breitwisch 1997). In areas where carotenoids are especially limited due either to environmental gradients or densitydependence, one would expect that increased intraspecific competition would constrain individual access to carotenoids and, thus, increase variation in plumage coloration among individuals. In this way, high variation in carotenoid-based coloration among individuals might be an indicator of the availability of reduced carotenoids in a particular environment. My findings suggest that despite greater densities of breeding pairs in 
urban landscapes (Leston and Rodewald 2006, Rodewald and Bakermans 2006), cardinals occupying urban forests were not more limited in access to carotenoids than individuals in more rural forests. Thus, supplemental food resources associated with residential land, such as birdfeeders and fruiting plants (Atchison and Rodewald 2006, Leston and Rodewald 2006) may permit high densities of cardinals to utilize similar per capita food resources as birds living in more rural environments. This scenario of apparent resource-matching is consistent with patterns recently reported by Rodewald and Shustack (2008), who showed that survival, reproductive productivity, and energetic condition of cardinals were similar across the rural-to-urban gradient (Rodewald and Shustack 2008).

Although the absence of a relationship between coloration and urbanization suggests that development surrounding forests does not influence their ability to acquire carotenoid-rich foods, there are a number of important caveats. First, given that cardinal coloration increases with age (Wolfenbarger 1996), I cannot exclude the possibility that different age structures in urban and rural populations masked patterns. Second, there is a possibility that cardinals molted and grew feathers at different locations than where they were captured, and therefore, may reflect different food conditions. However, cardinals in my study system (1) establish breeding territories beginning in March (2) generally molt in August while still on territory, and (3) show high site fidelity in this Ohio study system across years. Third, I focused only on plumage coloration, and other ornaments (e.g. mask, crown, and beak coloration) of cardinals also may be important indicators of quality (Jawor and Breitwisch 2004). 
To my knowledge, results from this study are among just a few that have provided insight into how plumage coloration of avian species changes with the amount of urbanization surrounding inhabited environments. Although urban anthropogenic disturbances do not appear to influence the plumages of Northern Cardinals, continued study is needed to identify and understand underlying impacts that urbanization may be having on avian plumage colorations.

\section{Acknowledgements}

My honors research was generously supported by a Schwab Asc. Scholarship grant from The Ohio State University, College of Biological Sciences and an REU supplement from NSF (DEB-0639429 to Amanda D. Rodewald). Field components of this research were partially supported by the National Science Foundation (DEB-0340879 and DEB- 0639429 to Amanda D. Rodewald) and Ohio Division of Wildlife. I would like to thank my advisor Dr. Amanda Rodewald for her guidance and helpful comments in the development of this thesis. I would also like to thank my other committee members, Dr. Paul Rodewald and Dr. Mitch Masters, for their additional perspectives and comments. Thanks to Daniel Shustack, Laura Kearns, Ian Ausprey, and Jennifer Smith-Castro for their mentoring and dedicated work in the field, which were essential in the completion of this project. I thank the following technicians for their work in the field: B. Adams, E. Ames, C. Austin, S. Buescher, L. Koerner, S. Lehnen, W. Li, L. MacArthur, A. Petersen, J. Price, L. Rogers, K. Uppstrom, B. Van Allen, and R. Zajac. I am grateful to the Franklin County Metro Parks, Columbus Parks and Recreation, Ohio Division of 
Wildlife, The Nature Conservancy, City of Bexley, Gahanna Parks and Recreation, and private landowners for their cooperation and access to sites.

\section{Literature Cited}

Anderies, J. M., K. Madhusudan, and E. Shochat. 2007. Living in the city: Resource availability, predation, and bird population dynamics in urban areas. Journal of Theoretical Biology 247: 36-49.

Andersson, M. B. 1994. Sexual selection. Princeton University Press, Princeton, New Jersey.

Arriero, E. and J. A. Fargallo. 2006. Habitat structure is associated with the expression of carotenoid-based coloration in nestling blue tits (Parus caeruleus). Naturwissenschaften 93: 173-180.

Atchison, K. A., and A. D. Rodewald. 2006. The value of urban forests to wintering birds. 2006. Natural Areas Journal 26: 280-288.

Bennett, A. T. D., I. C. Cuthill, J. C. Partridge, and K. Lunau. 1997. Ultraviolet plumage colors predict mate preferences in starlings. Proc. Natl. Acad. Sci. USA 94: 86188621.

Bezzerides, L. A., K. J. McGraw, R. S. Parker, and J. Husseini. 2007. Elytra color as a signal of chemical defense in the Asian ladybird beetle Harmonia axyridis. Behav. Ecol. Sociobiol 61: 1401-1408.

Blair, R. B. 1996. Land use and avian species diversity along an urban gradient. Ecological Applications 6: 506-519.

Bortolotti, G. R. 2006. Natural selection and coloration: Protection, concealment, advertisement, or deception? In: Hill, G. E., and K. J. McGraw (eds). Bird 
Coloration: Evolution and Function, Volume II. Harvard University Press, Cambridge, Massachusetts, pg. 3-40.

Bortolotti, G. R., K. J. Fernie, and J. E. Smits. 2003. Carotenoid concentration and coloration of American Kestrels (Falco sparverius) disrupted by experimental exposure to PCBs. Functional Ecology 17: 651-657.

Cuthill, I. C. 2006. Color Perception. In: Hill, G. E., and K. J. McGraw (eds). Bird Coloration: Mechanisms and Measurements. Volume I. Harvard University Press, Cambridge, Massachusetts, pg. 3-35.

Dale, J. 2000. Ornamental plumage does not signal male quality in red-billed queleas. Proc. R. Soc. London 267: 2143-2149.

Dale, J. 2006. Inrtaspecific variation in coloration. In: Hill, G. E., and K. J. McGraw (eds). Bird Coloration: Function and Evolution. Volume II. Harvard University Press, Cambridge, Massachusetts, pg. 36-86.

Darwin, C. [1871] 1981. The descent of man, and selection in relation to sex. Princeton, New Jersey: Princeton University Press.

Dawson, R.D., and R. G. Bortolotti. 2006. Carotenoid-dependent coloration of American kestrels predicts ability to reduce parasitic infections. Naturwissenschaften 93: 597-602.

Devictor, V., R. Julliard, D. Couvet, A. Lee, and F. Jiguet. 2007. Functional homogenization effect of urbanization on bird communities. Conservation Biology 21: 741-751.

Eeva, T., E. Lehikoinen, and M. Ronka. 1998. Air pollution fades the plumage of the Great Tit. Functional Ecology 12: 607-612. 
Fitze, P. S., and H. Richner. 2002. Differential effects of a parasite on ornamental structures based on melanins and carotenoids. Behavioral Ecology 13:401-407.

Gerald, M. S., J. Bernstein, R. Hinkson, and R. A. E. Fosbury. 2001. Formal Method for Objective Assessment of Primate Color. J. Primatol. 53: 79-85.

Halkin, S. L., and S. U. Linville. 1999. Northern Cardinal (Cardinalis cardinalis). In: Poole, A., and F. Gill (eds). The Birds of North America, No. 440.

Hill, G. E. 1991. Plumage coloration is a sexually selected indicator of male quality. Nature 350: 337-339.

Hill, G. E., C. Y. Inouye, and R. Montgomerie. 2002. Dietary carotenoid predict plumage coloration in wild House Finches. Proc. R. Soc. London 269: 1119-1124.

Isaksson, C., and S. Andersson. 2007. Carotenoid diet and nestling provisioning in urban and rural great tits Parus major. Journal of Avian Biology 38: 564-572.

Isaksson, C., J. Ornborg, E. Stephensen, and S. Andersson. 2005. Plasma glutathione and carotenoid coloration as potential biomarkers of environmental stress in Great Tits. EcoHealth 2: 138-146.

Jawor, J. M., N. Gray, S. M. Beall, and R. Breitwisch. 2004. Multiple ornaments correlate with aspects of condition and behavior in female northern cardinals, Cardinalis cardinalis. Animal Behaviour 67: 875-882.

Jawor, J. M., R. Breitwisch. 2004. Multiple ornaments in male Northern Cardinals, Cardinalis cardinalis, as indicators of condition. Ethology 110: 113-126.

Jawor, J. M., S. U. Linville, S.M. Beall, and R. Breitwisch. 2003. Assortative mating by multiple ornaments in northern cardinals (Cardinalis cardinalis). Behavioral Ecology 14: 515-520 
Kilner, R. 1997. Mouth colour is a reliable signal of need in begging canary nestlings. Proceedings of the Royal Society of London. 264: 963-968.

Kilner, R., and N. B. Davies. 1998. Nestling mouth colour: ecological correlates of a begging signal. Animal Behaviour 56: 705-712.

Kristiansen, K. O., J. O. Bustnes, I. Folstad, and M. Helberg. 2006. Carotenoid coloration in great black-backed gull Larus marinus reflects individual quality. Journal of Avian Biology 37: 6-12.

Leston, L.F.V, and A. D. Rodewald. 2006. Are urban forests ecological traps for understory birds? An examination using northern cardinals. Biological Conservation 131: 566-574.

Linville, S. U., and R. Breitwisch. 1997. Carotenoid availability and plumage coloration in a wild population of Northern Cardinals. The Auk 114: 796-800.

Linville, S. U., R. Breitwisch, and A. J. Schilling. 1998. Plumage brightness as an indicator of parental care in Northern Cardinals. Anim. Behav. 55: 119-127.

Maney, D. L., A. K. Davis, C. T. Goode, A. Reid, and C. Showalter. 2008. Carotenoidbased plumage coloration predicts leukocyte parameters during the breeding season in Northern Cardinals (Cardinalis cardinalis). Ethology 114: 369-380.

McGraw, K. J., G. E. Hill, R. Stradi, and R. S. Parker. 2001. The influence of carotenoid acquisition and utilization on the maintenance of species-typical plumage pigmentation in male American Goldfinches (Carduelis tristis) and Northern Cardinals (Cardinalis cardinalis). Physiological and Biochemical Zoology 74: 843-852. 
Møller, A. P., C. Biard, J. D. Blount, D. C. Houston, P. Ninni, N. Saino, and P. F. Surai. 2000. Carotenoid dependent signals: indicators of foraging efficiency, immunocompetence or detoxification ability? Avian Poultry Sci Rev 11:137-159.

Mulvihill, R. S., K. C. Parkes, R. C. Leberman, and D. S. Wood. Evidence supporting a dietary basis for orange-tipped rectrices in the cedar waxwing. 1992. Journal of Field Ornithology 63: 212-216.

Quesada, J., and J. C. Senar. 2006. Comparing plumage colour measurements obtained directly from live birds and from collected feathers: the case of the Great Tit Parus major. Journal of Avian Biology 37: 609-616.

Rodewald, A. D., and D. Shustack. 2008. Consumer resource matching in urbanizing landscapes: are synanthropic species over-matching? Ecology 89: 515-521.

Rodewald, A.D., and M. H. Bakermans. 2006. What is the appropriate paradigm for riparian forest conservation? Biological Conservation 128, 193-200.

Saks, L., I. Ots, and P. Horak. 2003. Carotenoid-based plumage coloration of male greenfinches reflects health and immunocompetence. Oecologica 134: 301-307.

Senar, J. C., and J. Quesada. 2006. Absolute and relative signals: a comparison of melanin- and carotenoid-based patches. Behaviour 143: 589-595.

Surmacki, A. and J. K. Nowakowski. 2007. Soil and preen waxes influence expression of carotenoid-based plumage coloration. Naturwissenschaften 94: 829-835.

Tratalos, J., R. A. Fuller, K. L. Evans, R. G. Davies, S. E. Newson, J. J. D. Greenwood, and K. J. Gaston. 2007. Bird densities are associated with household densities. Global Change Biology 13: 1685-1695. 
Wolfenbarger, L. L. 1996. Fitness effects associated with red coloration of male Northern Cardinals (Cardinalis cardinalis). Ph.D. dissertation, Cornell University, Ithaca, New York.

Wolfenbarger, L. L. 1999a. Female mate choice in Northern Cardinals: is there a preference for redder males? Wilson Bulletin 111: 76-83.

Wolfenbarger, L. L. 1999b. Red coloration of male Northern Cardinals correlates with mate quality and territory quality. Behavioral Ecology 10: 80-90.

Wolfenbarger, L. L. 1999c. Is red coloration of male Northern Cardinals beneficial during the non-breeding season?: A test of status signaling. The Condor 111: 655663. 
Table 1. Land cover characteristics within a 1-km radius of 13 riparian-forest study sites in rural ( $\mathrm{n}=5$ sites) and urban ( $\mathrm{n}=8$ sites) landscapes in central Ohio, USA

\begin{tabular}{lccccccc}
\hline & Urban & No. & Forest & \multicolumn{3}{c}{ Proportion of 1-km-radius area covered } \\
\cline { 5 - 8 } Site & Index & Buildings* & Width $(\mathrm{m})$ & Agriculture & Lawn & Pavement & Road \\
\hline Public Hunting & -1.15 & 210 & 194 & 0.32 & 0.08 & 0.01 & 0.01 \\
Prairie Oaks & -1.12 & 58 & 148 & 0.47 & 0.12 & 0.03 & 0.02 \\
Three Creeks & -0.71 & 92 & 133 & 0.10 & 0.10 & 0.04 & 0.02 \\
South Galena & -0.57 & 185 & 163 & 0.14 & 0.30 & 0.02 & 0.01 \\
Galena & -0.48 & 360 & 277 & 0.15 & 0.22 & 0.04 & 0.02 \\
Elk Run & -0.16 & 812 & 167 & 0.31 & 0.27 & 0.06 & 0.05 \\
Woodside Green & 0.32 & 1227 & 104 & 0.11 & 0.40 & 0.07 & 0.05 \\
Rush Run & 0.75 & 1611 & 150 & 0.00 & 0.41 & 0.09 & 0.06 \\
Cherrybottom & 0.76 & 997 & 165 & 0.02 & 0.36 & 0.16 & 0.07 \\
Kenny & 0.89 & 1733 & 126 & 0.00 & 0.34 & 0.17 & 0.06 \\
Casto & 1.25 & 1776 & 202 & 0.00 & 0.42 & 0.20 & 0.08 \\
Lou Berliner & 1.26 & 2272 & 156 & 0.00 & 0.28 & 0.23 & 0.08 \\
Tuttle & 1.61 & 2285 & 160 & 0.00 & 0.34 & 0.30 & 0.09 \\
\hline
\end{tabular}

*Number of buildings per landscape 
Fig 1. Superimposed feathers of a male Northern Cardinal on a white $4.5 \times 7.5 \mathrm{~cm}$ note card. Feathers were superimposed in groups of three where possible. Band number, the number of feathers present, identification number, and the date of capture were recorded on each card for identification purposes.

Fig 2. Relationship between plumage hue and relative body condition of 131 male Northern Cardinals inhabiting riparian forests of central Ohio, 2006-2008.

Fig 3. Relationship between plumage saturation and relative body condition of 131 male Northern Cardinals inhabiting riparian forests of central Ohio, 2006-2008.

Fig 4. Relationship between plumage brightness and relative body condition of 131 male Northern Cardinals inhabiting riparian forests of central Ohio, 2006-2008.

Fig 5. Relationship between plumage hue and relative body condition of 149 female Northern Cardinals in habiting riparian forests of central Ohio, 2006-2008.

Fig 6. Variation in male Northern Cardinal plumage saturation among 13 study sites in central Ohio, 2006-2008. Each datum represents the standard error for each site over all years. 


\section{9 $5 / 7 / 07$ 6fth}




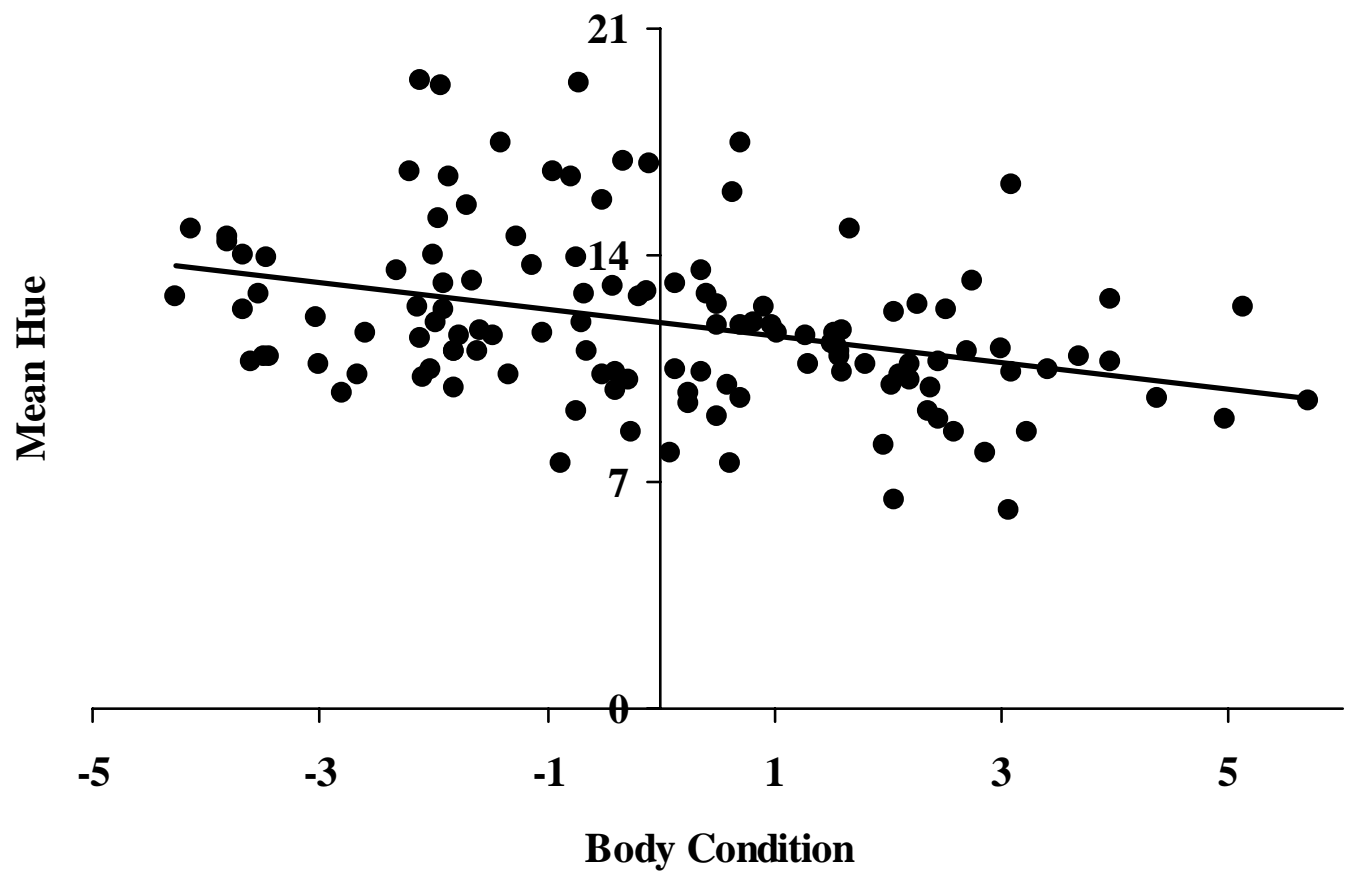




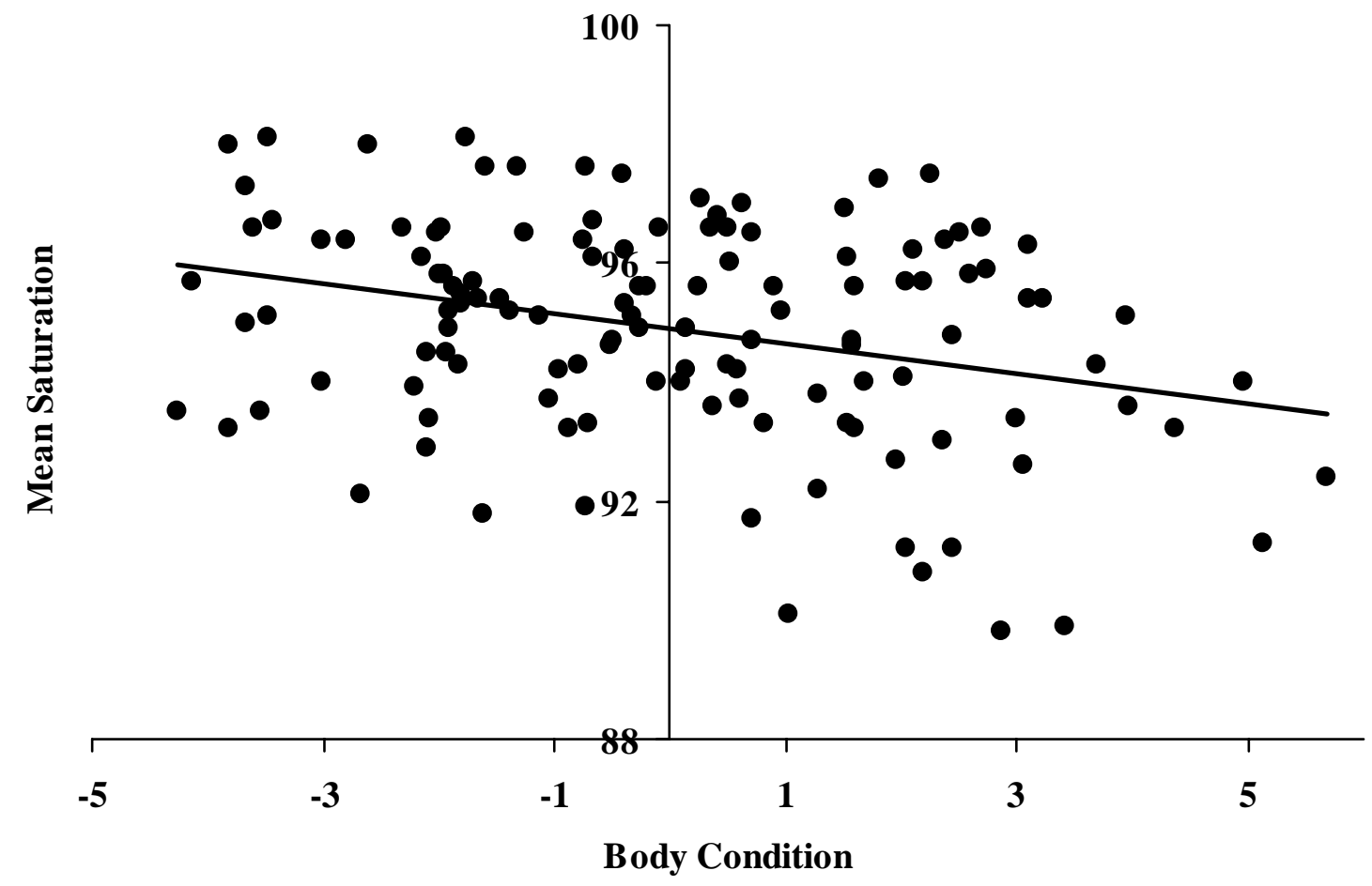




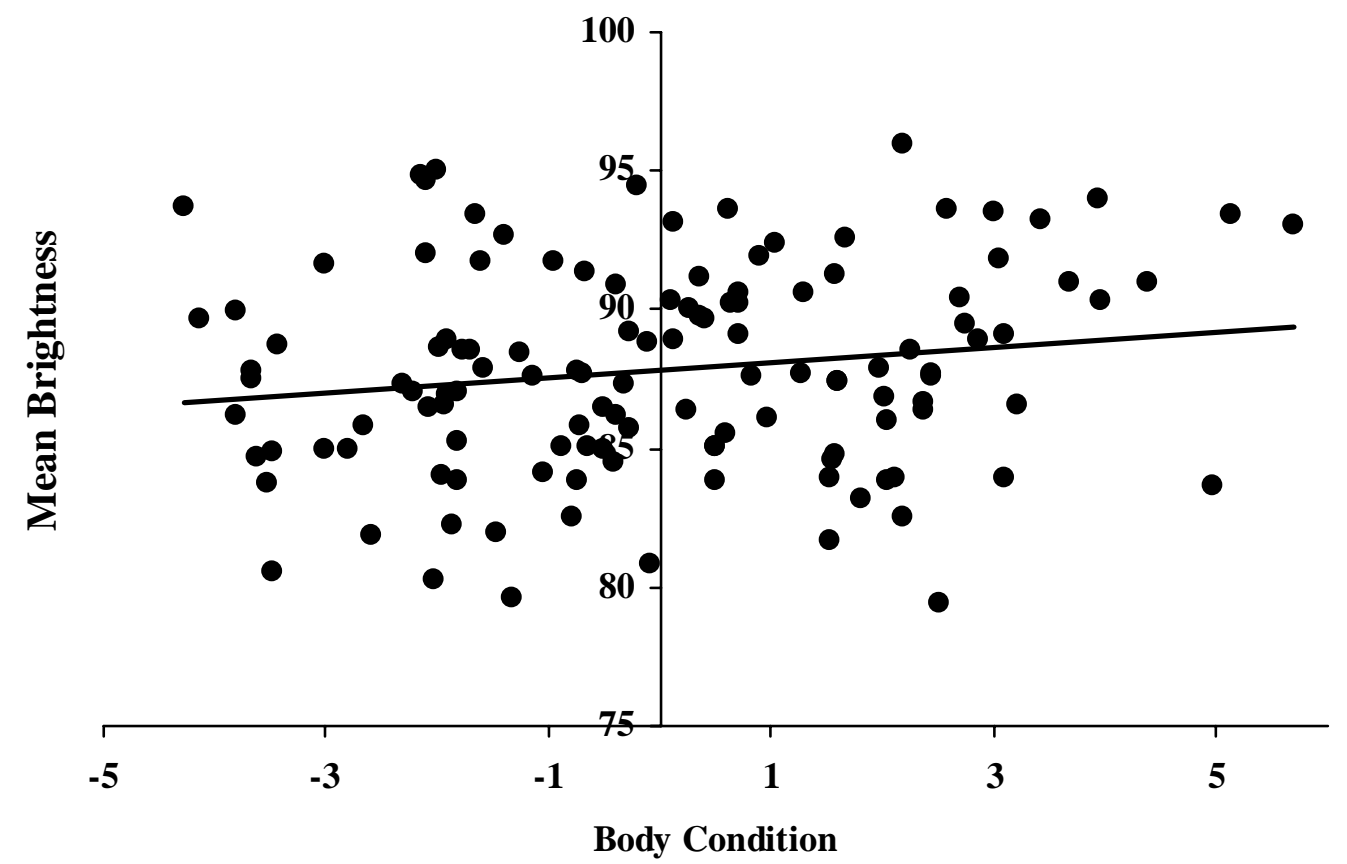




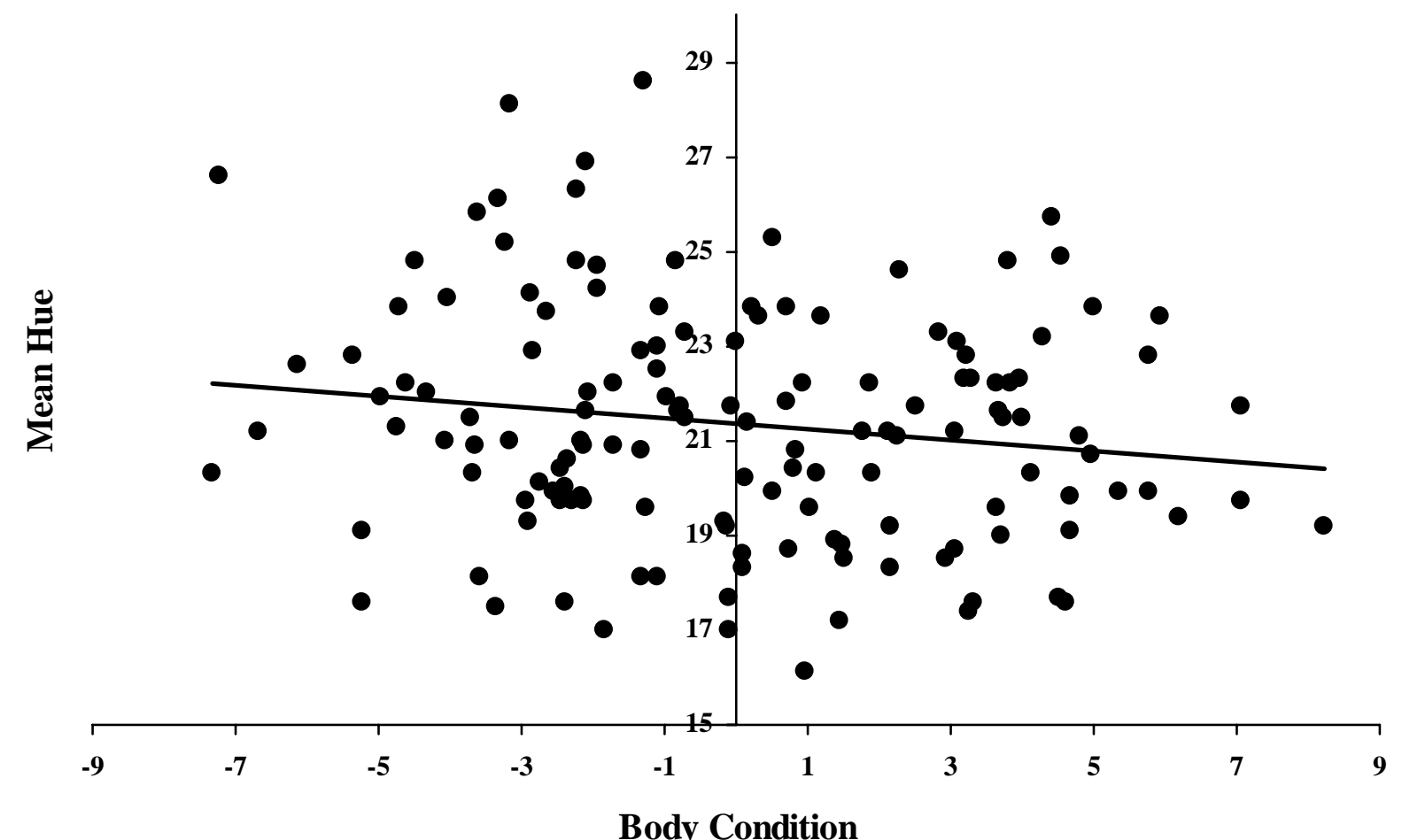

Body Condition 


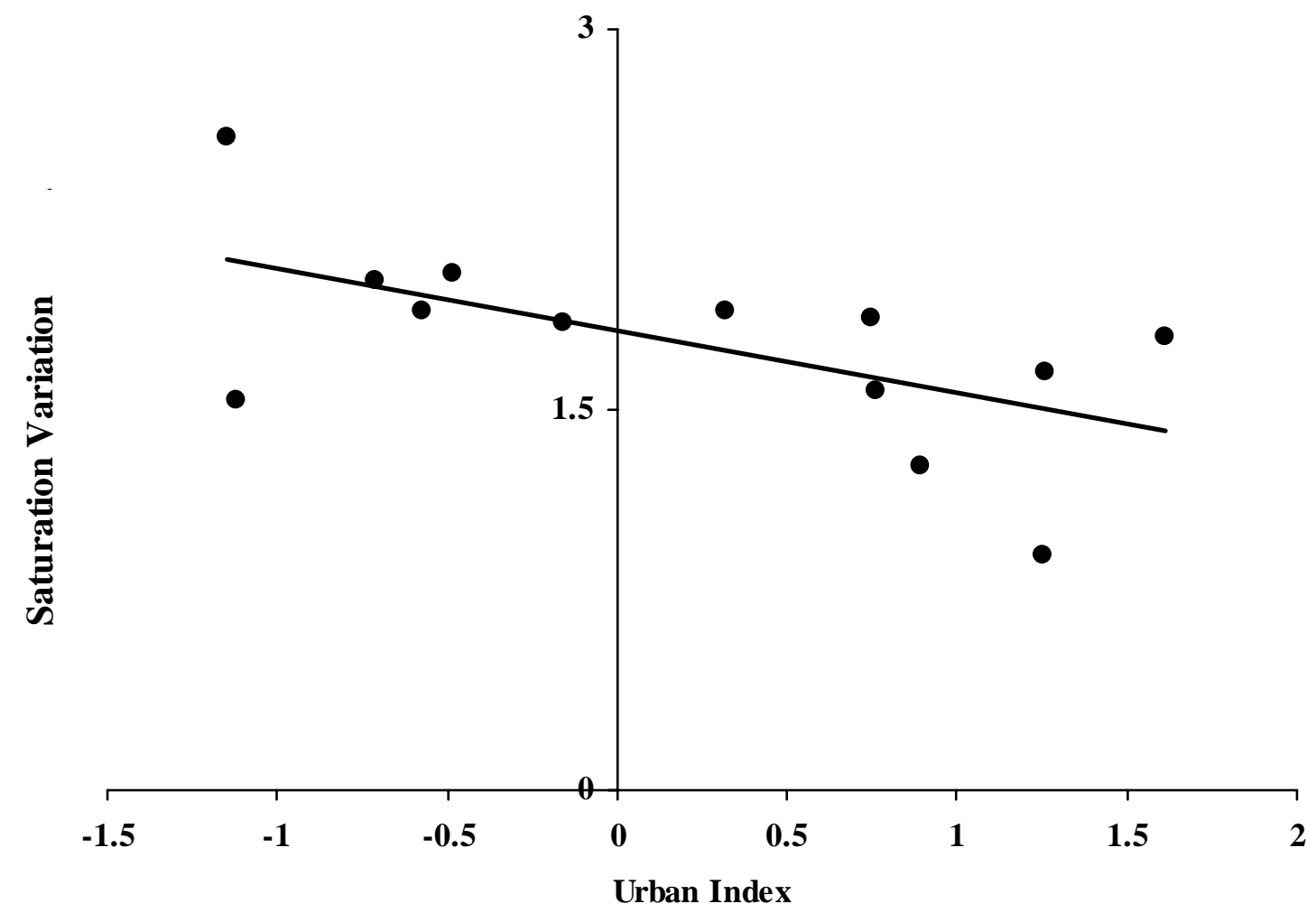


Appendix 1. Mean (SE) for plumage hue, saturation and brightness of Northern Cardinals in riparian forests of central Ohio, USA, 2006-2008

\begin{tabular}{|c|c|c|c|c|c|}
\hline \multicolumn{6}{|c|}{ Females } \\
\hline Site & $\begin{array}{l}\text { Urban } \\
\text { Index }\end{array}$ & $\begin{array}{c}\# \\
\text { Birds }\end{array}$ & Hue & Saturation & Brightness \\
\hline Public Hunting & -1.15 & 10 & $22.11(1.07)$ & $88.23(2.52)$ & $87.44(1.37)$ \\
\hline Prairie Oaks & -1.12 & 9 & $19.76(0.66)$ & $90.88(0.90)$ & 86.66 (1.67) \\
\hline Three Creeks & -0.71 & 5 & 21.24 (1.43) & 88.54 (1.65) & $85.94(2.16)$ \\
\hline S. Galena & -0.57 & 9 & $21.01(0.80)$ & 87.33 (1.37) & $88.07(1.36)$ \\
\hline Galena & -0.48 & 13 & $21.90(0.51)$ & 88.06 (1.73) & $86.32(1.16)$ \\
\hline Elkrun & -0.16 & 5 & $19.90(0.65)$ & $90.68(1.30)$ & 83.68 (4.19) \\
\hline Woodside Green & 0.32 & 9 & $22.67(0.56)$ & $85.28(1.08)$ & $89.11(0.88)$ \\
\hline Rushrun & 0.75 & 20 & $20.46(0.64)$ & $86.91(1.10)$ & $88.02(1.04)$ \\
\hline Cherrybottom & 0.76 & 12 & $21.84(0.70)$ & $88.50(1.64)$ & 86.53 (1.28) \\
\hline Kenny & 0.89 & 16 & $21.69(0.72)$ & 86.19 (1.66) & $86.41(0.55)$ \\
\hline Casto & 1.25 & 12 & 22.35 (1.04) & $83.76(2.03)$ & 84.15 (1.67) \\
\hline Lou Berliner & 1.26 & 14 & $20.37(0.55)$ & $89.09(1.04)$ & $86.09(1.26)$ \\
\hline Tuttle & 1.61 & 18 & $21.33(0.42)$ & $89.54(0.88)$ & $86.33(1.15)$ \\
\hline \multicolumn{6}{|c|}{ Males } \\
\hline Site & $\begin{array}{l}\text { Urban } \\
\text { Index }\end{array}$ & $\begin{array}{c}\# \\
\text { Birds }\end{array}$ & Hue & Saturation & Brightness \\
\hline Public Hunting & -1.15 & 9 & $10.93(0.94)$ & $93.40(0.91)$ & $88.90(1.37)$ \\
\hline Prairie Oaks & -1.12 & 5 & 11.38 (1.43) & $95.58(0.69)$ & $88.34(2.34)$ \\
\hline Three Creeks & -0.71 & 5 & $11.50(1.54)$ & $94.40(0.90)$ & $88.32(1.14)$ \\
\hline S. Galena & -0.57 & 9 & $10.49(0.46)$ & $94.89(0.63)$ & $88.31(1.45)$ \\
\hline Galena & -0.48 & 8 & $14.06(0.92)$ & $94.89(0.72)$ & 88.10 (1.67) \\
\hline Elkrun & -0.16 & 7 & $11.46(0.59)$ & $95.09(0.70)$ & 86.30 (1.05) \\
\hline Woodside Green & 0.32 & 8 & $10.46(0.53)$ & $94.04(0.67)$ & $88.21(0.73)$ \\
\hline Rushrun & 0.75 & 22 & $11.75(0.53)$ & $94.34(0.41)$ & $87.27(0.80)$ \\
\hline Cherrybottom & 0.76 & 6 & $12.40(0.87)$ & $94.90(0.64)$ & $88.15(0.36)$ \\
\hline Kenny & 0.89 & 19 & $12.26(0.47)$ & $95.42(0.30)$ & $89.76(0.96)$ \\
\hline Casto & 1.25 & 7 & $11.86(1.46)$ & $95.12(0.42)$ & 88.34 (1.97) \\
\hline Lou Berliner & 1.26 & 11 & $12.18(0.93)$ & $95.20(0.50)$ & 86.68 (1.23) \\
\hline Tuttle & 1.61 & 21 & $13.04(0.67)$ & $95.87(0.39)$ & $86.78(0.96)$ \\
\hline
\end{tabular}


Appendix 2. Mean (SE) for measurements of wing, weight, and tarsus of Northern Cardinals in riparian forests of central Ohio, USA, 2006-2008

\section{Females}

\begin{tabular}{|c|c|c|c|c|c|}
\hline \multicolumn{6}{|c|}{ \# } \\
\hline Site & Urban & Birds & Wing (mm) & Weight (g) & Tarsus (mm) \\
\hline Public Hunting & -1.15 & 10 & $91.15(0.31)$ & $42.25(1.07)$ & $23.98(0.21)$ \\
\hline Prairie Oaks & -1.12 & 9 & $89.83(0.39)$ & 44.11 (1.08) & $23.67(0.21)$ \\
\hline Three Creeks & -0.71 & 5 & $89.70(0.92)$ & $44.38(2.36)$ & $24.30(0.24)$ \\
\hline S. Galena & -0.57 & 9 & $92.22(0.65)$ & $46.11(1.50)$ & $24.04(0.25)$ \\
\hline Galena & -0.48 & 13 & $90.88(0.44)$ & $43.73(0.94)$ & $23.82(0.14)$ \\
\hline Elkrun & -0.16 & 5 & 89.80 (1.19) & $43.00(2.50)$ & $23.80(0.77)$ \\
\hline Woodside Green & 0.32 & 9 & $90.78(0.63)$ & $42.89(1.14)$ & $23.69(0.26)$ \\
\hline Rushrun & 0.75 & 20 & $91.03(0.58)$ & $43.45(0.64)$ & $23.93(0.15)$ \\
\hline Cherrybottom & 0.76 & 12 & 90.79 (0.69) & 43.38 (1.08) & $23.88(0.23)$ \\
\hline Kenny & 0.89 & 16 & $90.81(0.27)$ & $43.91(0.90)$ & $23.78(0.19)$ \\
\hline Casto & 1.25 & 12 & $89.42(0.65)$ & $43.21(0.95)$ & $24.03(0.26)$ \\
\hline Lou Berliner & 1.26 & 14 & $90.75(0.63)$ & $42.00(0.81)$ & $23.90(0.43)$ \\
\hline Tuttle & 1.61 & 18 & $90.67(0.36)$ & $42.59(0.98)$ & $23.57(0.27)$ \\
\hline \multicolumn{6}{|c|}{ Males } \\
\hline & & \# & & & \\
\hline Site & Urban & Birds & Wing (mm) & Weight (g) & Tarsus (mm) \\
\hline Public Hunting & -1.15 & 9 & $94.06(1.07)$ & $43.50(0.86)$ & $24.56(0.29)$ \\
\hline Prairie Oaks & -1.12 & 5 & $92.00(0.61)$ & $42.10(0.73)$ & $24.12(0.19)$ \\
\hline Three Creeks & -0.71 & 5 & $95.00(0.99)$ & $43.40(0.94)$ & $24.06(0.18)$ \\
\hline S. Galena & -0.57 & 9 & $94.17(0.52)$ & $43.33(0.74)$ & $24.27(0.14)$ \\
\hline Galena & -0.48 & 8 & $94.19(0.43)$ & $42.42(1.24)$ & $24.65(0.63)$ \\
\hline Elkrun & -0.16 & 7 & $93.29(0.83)$ & $43.50(0.80)$ & $24.63(0.31)$ \\
\hline Woodside Green & 0.32 & 8 & $93.31(0.50)$ & $43.50(0.82)$ & $24.16(0.30)$ \\
\hline Rushrun & 0.75 & 22 & $93.64(0.57)$ & $42.73(0.52)$ & $24.10(0.15)$ \\
\hline Cherrybottom & 0.76 & 6 & $93.67(0.86)$ & $43.42(0.90)$ & $24.38(0.30)$ \\
\hline Kenny & 0.89 & 19 & $92.68(0.56)$ & $42.50(0.57)$ & $24.55(0.13)$ \\
\hline Casto & 1.25 & 7 & $92.86(1.08)$ & $42.36(0.56)$ & $24.40(0.21)$ \\
\hline Lou Berliner & 1.26 & 11 & 93.95 (0.59) & $41.82(0.73)$ & $24.50(0.25)$ \\
\hline Tuttle & 1.61 & 21 & $94.15(0.46)$ & $41.61(0.51)$ & $23.76(0.18)$ \\
\hline
\end{tabular}

